СОВРЕМЕННЫЕ МЕТОДЫ ДИАГНОСТИКИ ПРЕДРАКОВЫХ И РАКОВЫХ ИЗМЕНЕНИЙ СЛИЗИСТОЙ ОБОЛОЧКИ РТА

\author{
(C) Г.С. Межевикина, Е.А. Глухова
}

Рязанский государственный медицинский университет имени академика И.П. Павлова, Рязань, Российская Федерация

В наше время онкологическая заболеваемость и борьба с ней являются важными задачами в медицине, и в стоматологии в частности. По данным литературных источников каждый год в России выявляется около 6000 больных раком ротовой полости. Так, за последние 15 лет заболеваемость раком слизистой оболочки рта (СОР), глотки, гортани возросла на 1517\%, а почти 90\% больных это работоспособные люди (30-60 лет). Несмотря на достаточно удобную для осмотра локализацию новообразований, большинство больных обращаются за лечением с опухолевыми процессами на III-IV стадии. Предраковые состояния в большинстве случаев предшествуют раку. Предрак длительное время не вызывает у пациентов жалоб, в связи с чем часто не диагностируется на ранних стадиях. Большие трудности возникают при дифференциации предрака с началом малигнизации. Поэтому очень важно своевременное их выявление и лечение, что увеличивает шанс предупреждения развития рака и повышение выживаемости пациентов. Распознавание ранних форм рака предупреждает запущенность злокачественного процесса, а лечение опухоли на ранних стадиях способствует снижению смертности, что решает важную медико-биологическую и социальную задачу онкологии. Данная статья это обзор современных литературных данных, касающихся диагностики предраковых и раковых изменений слизистой оболочки рта. В статье рассматриваются как широко используемые методы, так и новейшие технологии, которые в перспективе должны помочь врачам в диагностике предраковых и раковых изменений слизистой оболочки рта на ежедневном стоматологическом приеме.

Ключевые слова: диагностика, предрак, рак, слизистая оболочка рта.

\title{
MODERN DIAGNOSTIC METHODS PRECANCEROUS AND CANCEROUS CHANGES OF THE ORAL MUCOSA
}

(C) G.S. Mezhevikina, E.A. Glukhova

Ryazan State Medical University, Ryazan, Russian Federation

In our time cancer incidence and control are the most important tasks in medicine, and in dentistry in particular. According to the literature, every year in Russia for the first time revealed about 6000 patients with oral cancer. Over the past 15 years, the incidence of cancer of the oral mucosa, pharynx, larynx increased by $15-17 \%$, and most importantly, almost $90 \%$ of patients are working people (30-60 years old). Despite the rather convenient for exploring the localization of tumors, the majority of patients act on treatment with locally-spread tumors (III-IV stages). Precancerous in most cases precedes cancer. Precancer for a long time does not cause complaints in patients, and therefore is often not diagnosed in the early stages. Great difficulties arise in the differentiation of precancerous with the beginning of malignancy. Therefore, it is very important 
to timely detection and treatment, which increases the chance of cancer prevention and increase patient survival. Recognition of early forms of cancer prevents the neglect of the malignant process, and the treatment of tumors in the early stages helps to reduce mortality, which solves an important biomedical and social problem of oncology. This article is a review of current literature data concerning the diagnosis of precancerous and cancerous changes of the oral mucosa. The article discusses widely used methods and the latest technologies which ultimately should help doctors in the diagnostics of precancer and cancer of oral mucosa on daily work.

Keywords: diagnostics, precancer, cancer, oral mucosa.

В наше время онкологическая заболеваемость и борьба с ней являются важными задачами в медицине, и в стоматологии в частности $[1,2]$.

По данным Международного фонда исследований рака (World Cancer Research Fund International, WCRFI) онкологическая заболеваемость и смертность напрямую связана с уровнем развития экономики и, несмотря на достаточно высокий уровень жизни в мире, продолжает постоянно расти [3].

По данным ВО3 (1993) поражение раком органов и тканей рта находится на 4 месте, после рака легкого, желудка и колоректальной зоны [4].

По данным литературных источников каждый год в России выявляется около 6000 больных раком ротовой полости. Около 40\% всей заболеваемости раком головы и шеи приходится на долю рака COP. По частоте встречаемости после рака гортани рак СОР занимает 2 место. В структуре онкологической заболеваемости России рак СОР составляет $1,5 \%$ от всех онкологических заболеваний различных органов и систем [3,1].

За последние 15 лет заболеваемость раком СОР, глотки, гортани возросла на $15-17 \%$, а почти $90 \%$ больных это работоспособные люди (30-60 лет). Несмотря на достаточно удобную для осмотра локализацию новообразований 60-70\% больных, по данным Лазаревой В.А., обращаются за лечением с опухолевыми процессами на III-IV стадии [5].

Опухоли челюстно-лицевой области разнообразны как по морфологическому строению, так и по вариабельности клинических проявлений, в связи с чем ран- няя диагностика и лечение данных заболеваний до настоящего времени представляют трудность [6].

Предраковые состояния в большинстве случаев предшествуют раку. Под понятием предрака подразумеваются хронические воспалительные процессы, доброкачественные новообразования, нарушения процесса кератинизации, атипичное ороговение [6].

По данным современных литературных источников предраки составляют от 15,2 до 84,9\% всех заболеваний СОР [7].

Предрак длительное время не вызывает у пациентов жалоб, в связи с чем часто не диагностируется на ранних стадиях. Большие трудности возникают при дифференциации предрака с началом малигнизации из-за многообразия предраковых заболеваний по клиническому течению, морфологии, а на ранних стадиях малигнизации вследствие отсутствия четких клинических признаков [6].

Общеизвестна высокая вероятность перехода предраковых заболеваний в злокачественные, поэтому очень важно своевременное их выявление и лечение, что увеличивает шанс предупреждения развития рака и повышение выживаемости пациентов [4].

Распознавание ранних форм рака предупреждает запущенность злокачественного процесса, а лечение опухоли на ранних стадиях способствует снижению смертности, что решает важную медикобиологическую и социальную задачу онкологии [5].

Стандартный алгоритм диагностики включает в себя опрос и осмотр. Наиболее часто используются визуальный и визу- 
ально-инструментальный методы, а также применяют цитологические, гистологические методы, методики витального окрашивания, стоматоскопию, биомикроскопию. Существуют и гистохимический метод, цитометрия ДНК, люминесцентное, радиоизотопное исследования, электронная микроскопия. Перспективна разработка методики спектроскопии [4].

Гистологический метод является основным методом дифференциальной диагностики у врача-стоматолога [6]. При данном исследовании материала пользуются двумя классификациями: клинической классификацией А.Л. Машкилейсона (1970) и классификацией ВО3 (2005).

Для оценки степеней дисплазии, по классификации ВО3, врачи используют плоскоклеточную внутриэпителиальную неоплазию (Squamous Intraepithelial Neoplasia - SIN) от 1 до 3 - в зависимости от тяжести дисплазии [8]. В данной классификации достаточно четко описаны стадии озлокачествления, однако практически оценить степень выраженности дисплазии бывает не всегда возможно, в связи с чем используют разнообразные дополнительные методики [9].

В настоящее время иммуногистохимическая диагностика позволяет достаточно четко провести дифференциальную диагностику различных новообразований для выявления экспрессии маркера пролиферации Ki-67, маркера апоптотической активности Р53 и белков клеточной адгезии. Именно данное исследование помогает определить степень дисплазии эпителия СОР, так как наличие клинических и гистологических данных не всегда позволяет точно оценить степень малигнизации.

Во всех фазах митотического цикла, кроме GO, в клетке наблюдается белок Ki-67 - универсальный маркер пролиферирующих клеток, который имеет важное прогностическое значение при разной степени дисплазии. Для гистологического исследования и иммуногистохимии срезы слизистой оболочки толщиной 5 мкм монтируют на стеклах. Индекс пролиферации по Кi-67 (ИП Кi$67)$ определяли отношением количества им- мунореактивных ядер клеток к общему числу ядер клеток в \% $[9,10]$.

При иммуногистохимическом исследовании СОПР во всех исследуемых препаратах в ядрах пролиферирующих клеток отмечалась выраженная экспрессия по Кi-67. В нормальном эпителии СОПР все иммунопозитивные клетки локализовались в базальном слое, тогда как при лейкоплакии (SIN1, SIN2 и SIN3) иммуногистохимическая реакция с антителами к Кi-67 обнаруживалась преимущественно в ядрах клеток базального и парабазального слоев. В неизмененном эпителии СОПР и при лейкоплакии, в поверхностных слоях количество этих клеток составляло менее $1 \%$. В плоскоклеточном раке архитектоника ткани была полностью нарушена и деление эпителия на слои практически отсутствовало. Положительно окрашенные клетки распределялись равномерно от базальной мембраны до поверхности эпителия. Для оценки пролиферативной активности в нормальном эпителии СОПР, лейкоплакии и плоскоклеточном раке были подсчитаны позитивно окрашенные клетки на Ki-67 во всех слоях эпителия (ИП 0) и отдельно.

В ходе ряда исследований при плоскоклеточном раке отмечается наиболее высокий индекс пролиферации, а также выявляется зависимость между повышением индекса пролиферации эпителия по Ki-67 и увеличением степени дисплазии эпителия. По данным Ковязина В.А. и соавт. выявлено, что пролиферативная активность клеток базального слоя эпителия СОПР падает по мере увеличения степени неоплазии, тогда как в парабазальном слое данный показатель возрастает [9].

При иммуногистохимии неизмененного многослойного плоского эпителия выраженная экспрессия клаудин-1 отмечается в клетках базального, парабазального и шиповатого слоев. Так при гиперплазии высокая степень клеточной пролиферации проявляется снижением уровня экспрессии клаудин-1, а выраженная неоплазия - полным отсутствием данного белка на поверхности клеток [10]. 
По данным современных исследований присутствие белка Р53 отмечается в ядрах клеток всех слоев эпителия СОР, в нормальном эпителии и при всех видах лейкоплакии. При нарастании явлений дисплазии во всех слоях эпителия происходит увеличение количества клеток с данным белком, максимальное их количество при плоскоклеточном раке [6].

Иммуногистохимия используется также и для выявления антигенов HPV16 и белков, ассоциированных с HPV-P16INK4a в эпителиальных клетках при различных видах лейкоплакии, раке. Так, по данным ряда авторов повышенная экспрессия P16INK4a является непрямым показателем HPV и тем самым отражает нарушение механизмов, отвечающих за клеточную пролиферацию. Данный показатель также подтверждает присутствие инфекции с высоким риском развития неоплазии [11].

Оптическая когерентная томография (ОКТ) - это метод диагностики, основанный на получении изображения микроструктуры тканей используя свет ближнего инфракрасного диапазона [11,12].

По данным современных литературных источников данный метод исследования основан на различии оптических свойств тканей в зависимости от их структуры. С помощью ОКТ становится возможным получить изображения подповерхностных структур на глубине до 2 мм. Данный метод используют в клинической практике для дифференциальной диагностики клинически похожих заболеваний, предраков и рака, фиксирования границ злокачественного новообразования, определения оптимального места для биопсии и также динамического наблюдения за состоянием СОР в процессе лечения [12].

По данным Рабинович О.Ф. и соавт., для описания ОКТ-изображений СОР используют такие понятия, как слоистость, структурность, характеристики границы, характер поверхности, оптическая неоднородность, глубина изображения, яркость, контрастность, Так, нормальная СОР характеризуется слоистым изображением в виде двух горизонтально ориен- тированных слоя. Основной признак малигнизации - потеря структурности, что подтверждается однородным гомогенным изображением с малой глубиной сигнала или его отсутствием [11].

В настоящее время большую популярность получают методы онкоскрининга. По данным современных литературных источников скрининг - это система первичного отбора лиц со скрыто протекающим заболеванием путем проведения простых, безопасных и недорогих методов с целью дальнейшего углубленного обследования [6,13].

На сегодняшний день достаточно широко используется аутофлуоресцентная стоматоскопия. В основе данного метода лежит различие интенсивности и спектрального состава эндогенного (аутофлуоресцентного) излучения здоровых тканей и патологических очагов при возбуждении в УФ-спектре. В месте имеющегося злокачественного новообразования отмечается резкое снижение интенсивности аутофлуоресцентного излучения $[10,1]$.

По данным Булгаковой Н.Н. и соавт. при аутофлуоресцентной диагностике неизмененная слизистая оболочка обладает зеленоватым свечением. Красное свечение характерно для очагов воспаления, вследствие наличия эндогенных порфиринов, на поверхности языка из-за налета из микроорганизмов и продуктов их жизнедеятельности. Очаги веррукозной лейкоплакии и красного плоского лишая визуализируются в виде темных участков без видимого свечения. Свечение с красновато-коричневым или розовым оттенком говорит о злокачественности процесса $[7,1]$.

При аутофлуоресцентном осмотре очаги поражения имеют большую площадь, чем при традиционном осмотре в белом свете. Проведение осмотра занимает несколько минут, является неинвазивным, бесконтактным и не требует применения дорогостоящих реактивов [7].

Метод люминоскопии (ОЛД-41) основан на способности тканей и клеток под действием ультрафиолетовых лучей изменять свой естественный цвет (с помощью 
лампы Вуда). Метод инфракрасной томографии (ИКТ) проводится с помощью инфракрасной камеры CEDIP Silver 450M. Данный метод является очень перспективным в целях ранней диагностики предраковых заболеваний СОР [14].

Для повышения онкологической настороженности необходимо использовать методы ранней визуализации митотических изменений в эпителии слизистой оболочки, клеточных и других изменений в тканях. В настоящее время широко применяется техника прямой визуализации флуоресценции тканей рта с использованием аппарата «VELscope Vx Enhanced Oral Assessment System». Данная методика позволяет обнаружить субклинические признаки предраковых и раковых изменений слизистой оболочки рта при отсутствии видимых признаков поражения. Скрининг, проводимый с помощью аппарата «VELscope Vx» позволяет также определить истинные границы видимых патологических процессов, которые выявляются значительно больших размеров чем при визуальном осмотре [15].
Скрининговый тест ViziLite Plus также является одним из методов диагностики предраковых заболеваний. Краситель, входящий в состав системы ViziLite Plus, обеспечивает стойкое окрашивание предраковых и раковых клеток СОР, и тем самым делает эти клетки видимыми при обычном освещении. Степень интенсивности окрашивания атипичных поражений тканей рта напрямую отражает степень выраженности диспластических процессов в этих тканях [16].

Заключение: вопрос профилактики и своевременной диагностики предраковых и раковых заболеваний является очень актуальным в настоящее время. Стоматологам отводится важная роль в решении данного вопроса. На них ложится задача санитарно-гигиенического воспитания широких слоев населения, привития желания регулярно посещать врача-стоматолога. Параллельно необходимо продолжать активную работу по использованию известных методов диагностики, а также разработку новых способов обнаружения проявлений атипии в полости рта $[3,4]$.

\section{Литература}

1. Булгакова Н.Н., Волков Е.А., Позднякова Т.И. Аутофлуоресцентная стоматоскопия как метод онкоскрининга заболеваний слизистой оболочки рта // Российский стоматологический журнал. 2015. Т. 19, №1. С. 27-30.

2. Родина Т.С. Особенности стоматологической патологии у лиц старших возрастных групп // Российский медико-биологический вестник имени академика И.П. Павлова. 2015. Т. 23, №3. C. 140-147.

3. Ахмадова М.А., Сойхер М.И., Чуянова Е.Ю. Онконастороженность в практике врачастоматолога // Медицинский алфавит. 2016. T. 2, №9. C. 6-9.

4. Гончарова Е.И., Спицына В.И. Клинические аспекты предрака слизистой оболочки рта и красной каймы губ, повышение эффективности диагностики и лечения // Российский стоматологический журнал. 2008. №4. С. 10-14.

5. Лазарева В.А. Значение параметров перекисного окисления липидов в прогнозировании исходов заболевания у больных злокачественными опухолями орофарингеальной зоны. Дис... канд. мед. наук. Нижний Новгород; 2010.
6. Лаптев П.И., Воложин А.И. Диагностика и лечение предраков красной каймы губы и слизистой оболочки органов полости рта // Российский стоматологический журнал. 2004. №4. С. 13-15.

7. Крихели Н.И., Позднякова Т.И., Булгакова Н.И. и др. Результаты аутофлюоресцентной стоматоскопии плоского лищая как скринингового метода выявления предраковых и раковых изменений слизистой оболочки рта // Российская стоматология. 2016. №4. С. 13-17.

8. Сулимов А.Ф., Кузнецова А.Б. Клиническая значимость морфологических методов диагностики слизистой оболочки полости рта и красной каймы губ с целью выявления ранних признаков малигнизации // Российский стоматологический журнал. 2013. №2. С. 30-32.

9. Ковязин В.А., Григорьян А.С., Катушкина А.А. и др. Особенности экспрессии белка Кi-67 при лейкоплакии и плоскоклеточном раке слизистой оболочки полости рта // Стоматология. 2010. №6. C. 4-6.

10. Ивина А.А., Бабиченко И.И., Рабинович О.Ф. и др. Белки Кі-67 и клаудин-1 при гиперплазии, плоскоклеточной внутриэпителиальной неоплазии и плоскоклеточном раке слизистой оболочки рта // Стоматология. 2014. №1. С. 31-33. 
11. Рабинович О.Ф., Бабиченко И.И., Рабинович И.М. и др. Методы комплексной диагностики лейкоплакии слизистой оболочки рта // Стоматология. 2014. №5. С. 19-22.

12. Гладкова Н.Д., Масленникова А.В., Балалаева И.В. и др. Возможности оптической когерентной томографии в диагностике мукозита у больных раком полости рта и глотки в процессе лучевого и химиолучевого лечения // Вопросы онкологии. 2006. Т. 52, №4. С. 443-446.

13. Уткин Д.О., Баранова Е.А., Рязанцев М.Е. и др. Проблема скрининга рака шейки матки (на примере Рязанской области) // Наука молодых. (Eruditio Juvenium). 2015. №4. C. 82-90.

14. Гилева О.С., Либик Т.В. Предраковые заболевания в структуре патологии слизистой оболочки полости рта // Проблемы стоматологии. 2013. №2. C. 3-9.

15. Гажва С.И., Степанян Т.Б., Горячева Т.П. Распространенность стоматологических заболеваний слизистой оболочки полости рта и их диагностика // Международный журнал прикладных и фундаментальных исследований. 2014. №5. С. 41-44.

16. Сулимов А.Ф., Демянчук А.Б. Скрининг атипичных поражений слизистой оболочки рта // Стоматология. 2015. №5. С. 79-81.

\section{References}

1. Bulgakova NN, Volkov EA, Pozdnjakova TI. Autofluorescent dentistry as a method of oncoscreening of diseases of the oral mucosa. Rossijskij stomatologicheskij zhurnal. 2015;19(1):27-30. (In Russ).

2. Rodina TS. Features of dental pathology in older age groups. I.P. Pavlov Russian Medical Biological Herald. 2015;23(3):140-7. (In Russ).

3. Ahmadova MA, Sojher MI, Chujanova EJu. Onconfidence in the practice of a dentist. Medicinskij alfavit. 2016;2(9):6-9. (In Russ).

4. Goncharova EI, Spicyna VI. Clinical aspects of precancer of the oral mucosa and red lip rim, increasing the efficiency of diagnosis and treatment. Rossijskij stomatologicheskij zhurnal. 2008;(4):104. (In Russ).

5. Lazareva V.A. Znacheniye parametrov perekisnogo okisleniya lipidov $v$ prognozirovanii iskhodov zabolevaniya u bol'nykh zlokachestvennymi opukholyami orofaringeal'noy zony [dissertation]. Nizhniy Novgorod; 2010. (In Russ).
6. Laptev PI, Volozhin AI. Results of autofluorescent dentoscopy of a flat leaf as a screening method for detecting precancerous and cancerous changes in the oral mucosa. Rossijskij stomatologicheskij zhurnal. 2004;(4):13-5. (In Russ).

7. Kriheli NI, Pozdnjakova TI, Bulgakova NI, i dr. Results of autofluorescent dentoscopy of a flat leaf as a screening method for detecting precancerous and cancerous changes in the oral mucosa. Rossijskaja stomatologija. 2016;(4):13-7. (In Russ).

8. Sulimov AF, Kuznecova AB. Clinical significance of morphological methods of diagnosis of the oral mucosa and red lip rim for the purpose of identifying early signs of malignancy. Rossijskij stomatologicheskij zhurnal. 2013;(2):30-2. (In Russ).

9. Kovjazin VA, Grigor'jan AS, Katushkina AA, et al. Peculiarities of Ki-67 protein expression in leukoplakia and squamous cell carcinoma of the oral mucosa. Stomatologija. 2010;(6):4-6. (In Russ).

10. Ivina AA, Babichenko II, Rabinovich OF, et al. Proteins Ki-67 and claudine-1 for hyperplasia, squamous intraepithelial neoplasia and squamous cell carcinoma of the oral mucosa. Stomatologija. 2014;(1):31-3. (In Russ).

11. Rabinovich OF, Babichenko II, Rabinovich IM, et al. Methods for the complex diagnosis of leukoplakia of the oral mucosa. Stomatologija. 2014;(5):19-22. (In Russ).

12. Gladkova ND, Maslennikova AV, Balalaeva IV, et al. Possibilities of optical coherence tomography in the diagnosis of mucositis in patients with oral and pharyngeal cancer in the process of radiation and chemoradiation treatment. Voprosy onkologii. 2006;52(4):443-6. (In Russ).

13. Utkin DO, Baranova EA, Ryazantcev ME, et al. The problem of cervical cancer screening (on the example of the Ryazan region). Science of the young (Eruditio Juvenium). 2015;(4):82-90. (In Russ).

14. Gileva OS, Libik TV. Precancerous diseases in the structure of pathology of the oral mucosa. Problemy stomatologii. 2013;(2):3-9. (In Russ).

15. Gazhva SI, Stepanjan TB, Gorjacheva TP. The prevalence of dental diseases of the oral mucosa and their diagnosis. Mezhdunarodnyj zhurnal prikladnyh $i$ fundamental'nyh issledovanij. 2014;(5):41-4. (In Russ).

16. Sulimov AF, Demjanchuk AB. Screening of a typical lesions of the oral mucosa. Stomatologija. 2015; 23(3):140-7. (In Russ).

\section{Информация об авторах [Authors Info]}

\footnotetext{
*Межевикина Галина Сергеевна - к.м.н., доцент кафедры терапевтической и детской стоматологии ФГБОУ ВО Рязанский государственный медицинский университет имени академика И.П. Павлова Минздрава России, г. Рязань, Российская Федерация. е-таil: galinasyx@yandex.ru SPIN: 3041-8738, ORCID ID: 0000-0001-7937-3501.

Galina S. Mezhevikina - PhD, Assistant Professor of the Department of Therapeutic and Pediatric Dentistry, Ryazan State Medical University, Ryazan, Russian Federation. e-mail: galinasyx@yandex.ru SPIN: 3041-8738, ORCID ID: 0000-0001-7937-3501.
} 
Глухова Елена Александровна - к.м.н., доцент кафедры терапевтической и детской стоматологии ФГБОУ ВО Рязанский государственный медицинский университет имени академика И.П. Павлова Минздрава России, г. Рязань, Российская Федерация.

SPIN: 1312-4931, ORCID ID: 0000-0002-6701-8091.

Elena A. Glukhova - PhD, Assistant Professor of the Department of Therapeutic and Pediatric Dentistry, Ryazan State Medical University, Ryazan, Russian Federation.

SPIN: 1312-4931, ORCID ID: 0000-0002-6701-8091.

Цитировать: Межевикина Г.С., Глухова Е.А. Современные методы диагностики предраковых и раковых изменений слизистой оболочки рта // Наука молодых (Eruditio Juvenium). 2018. Т. 6, №4. С. 600-606. doi:10.23888/HMJ201864600-606

To cite this article: Mezhevikina GS, Glukhova EA. Modern diagnostic methods precancerous and cancerous changes of the oral mucosa. Science of the young (Eruditio Juvenium). 2018;6(4):600-6. doi:10.23888/HMJ201864600-606

Поступила / Received: 15.05 .2018

Принята в печать / Accepted: 17.12.2018 